\title{
Neurovascular Evaluation in Eugonadal Men with Type 2 Diabetes Mellitus and Erectile Disfunction: A Comparative Study between Responders and Not Responders to Phosphodiesterase 5 Inhibitors
}

\author{
Marcelo Rodriguez Peña*, Elizabeth Ovando \\ Andrology and Reproductive Medicine Program, IAMED, Buenos Aires, Argentina \\ Email: "
}

Received 14 August 2015; accepted 5 October 2015; published 8 October 2015

Copyright (C) 2015 by authors and Scientific Research Publishing Inc.

This work is licensed under the Creative Commons Attribution International License (CC BY).

http://creativecommons.org/licenses/by/4.0/

(c) (i) Open Access

\section{Abstract}

The aim of our study was to evaluate functional alterations of the corpus cavernusum and its correlation with the lack of response to treatment with PDE5i in eugonadal patients with Type 2 Diabetes Mellitus and Erectile Dysfunction. In this prospective randomized study we included 157 patients. All were treated with $5 \mathrm{mg}$ tadalafil daily and $100 \mathrm{mg}$ sildenafil on demand and the response to treatment was assessed in 6 month by dividing them into 2 groups: G1: Good response. Significative improvement of erectile function according to IIEF-5, and G2: There was not an improvement with the treatment. At the end of the treatment we performed neurological and vascular studies to both groups. Also we performed CC-EMG in order to evaluate penile autonomic neuropathy. 82 patients were included in $\mathrm{G1}$ and 75 in G2. The time evolution of the ED was 1.5 years for G1 and 5 years for G2. Average fasting glucose and glycosilated hemoglobin values were significantly higher in G2 than in G1. Also we observed significant differences in penile vascular parameters between both groups. Peripheral neuropathy parameters did not show differences between both groups. Cavernous smooth muscle electromyography showed asynchronous and asymetric potentials in G1 (minimal autonomic neuropathy) and denervation potentials in G2 characteristic of severe $\mathrm{CC}$ damage. It is concluded that vascular and autonomic alterations are causes of severe CC damage and lack of response to treatment with PDE5i in this population. Peripheral neuropathy is not part of this process.

${ }^{*}$ Corresponding author.

How to cite this paper: Rodriguez Peña, M. and Ovando, E. (2015) Neurovascular Evaluation in Eugonadal Men with Type 2 Diabetes Mellitus and Erectile Disfunction: A Comparative Study between Responders and Not Responders to Phosphodiesterase 5 Inhibitors. Advances in Sexual Medicine, 5, 83-88. http://dx.doi.org/10.4236/asm.2015.54010 


\section{Keywords}

\section{Erectile Dysfunction, Type 2 Diabetes Mellitus, Corpus Cavernosum Damage}

\section{Introduction}

Erectile Disfunction (ED) is the most frequent cause of sexual dysfunction in diabetic male patients with an estimated incidence of 35\% - 75\% [1] [2].

ED is defined as the inability to achieve or maintain an adequate erection to allow a satisfactory sexual intercourse. This situation should be evident for several months and should occur in at least half of the attempts [3].

ED is a generalized vascular disease marker and early diagnosis in patients with type II diabetes mellitus (DM) prevents cardiovascular events such as myocardial infarction [4] [5].

The etiology of ED in diabetic patients is not correctly understood. Several factors have been involved such as neuropathy, vascular disease, metabolic syndrome, nutritional and endocrine disorders and drugs used in the treatment of DM [6]. Moreover, diabetic patients have comorbid factors such as hypertension and chronic renal failure that predispose to ED [1] [6].

Since the development of oral therapy with phosphodiesterase-5 inhibitors (PDE5i) the first line of treatment for these patients is using them. However a significant number of these patients do not respond to this therapy [7].

The purpose of this study is to evaluate neurological, vascular and autonomic alterations of the corpus cavernosum (CC) in patients with DM and ED and its correlation with the lack of response to treatment with PDE5i.

\section{Materials and Methods}

In this prospective randomized study we included 157 eugonadic patients (testosterone levels above $4 \mathrm{ng} / \mathrm{ml}$ and without symptoms of androgen deficiency according to the aging male simptoms scale) with DM and ED. All patients underwent a complete urological examination and completed items 1 to 5 of the International Index of Erectile Function [8]. All patients were treated with $5 \mathrm{mg}$ tadalafil daily and $100 \mathrm{mg}$ sildenafil on demand and the response to treatment was assessed in 6 months by dividing them into 2 groups: Group 1 (G1): Good response. Improvement of erectile function. $\mathrm{IIEF}_{5}$ higher than 26 points; and group 2 (G2): There was not an improvement with the treatment [9].

We determined the average fasting glucose (AFG) (defined as the average blood glucose values obtained at least in three opportunities during the 6 month treatment hard) and glycosilated hemoglobin (HbA1c) obtained at the end of the treatment.

Also at the end of the treatment we performed vascular and neurological studies to both groups. Penile vascular evaluation was assessed by doppler ultrasound using prostaglandine E1 as a vasoactive drug, measurement of peak systolic velocity (PSV) and end diastolic velocity (EDV).

Peripheral neuropathy (PN) evaluation was performed by measuring the latency of the bulbocavernous reflex (BCR), nervous conductance in lower limbs (NC) and pudendal cortical evoked potentials (PCEP)

The study of autonomic neuropathy (AN) was performed by cavernous smooth muscle electromyography by using contact electrodes (CC-EMG).

Finally, the level of satisfaction was assessed with the Life Satisfaction Check-List questionnaire (LSCL) [10]. This is a questionnaire that explores the patient's perception regarding to their satisfaction with life in general and other seven related domains by using a scale of 6 categories (from 1: very dissatisfied to 6: very satisfied).

All patients signed their consent to perform this study and it was approved by the ethics committee of our institution.

\section{Statistical Analysis}

Unpaired t-test was used to analyze LSCL questionnaire and the non parametric Mann-Whitney rank test was used to analyze AFG, HbA1c, vascular and neurophysiological parameters. Data represent mean \pm standard deviation. $P<0.05$ was considered significant. 


\section{Results}

The average age of the study population was 53 years (range 34 - 71). 82 patients showed good response to treatment (G1) according to International Index of Erectile Function and 75 did not respond (G2). The time evolution of the ED was 1.5 years for G1 and 5 years for G2.

AFG and HbA1c values were significantly higher in G2 than in G1 (Figure 1 and Figure 2) showing that this first group of patients have poor response to antidiabetic therapy or bad controls.

Penile vascular evaluation with Doppler ultrasound showed significant differences in vascular parameters between both groups (Figure 3 and Figure 4). Values of PSV are higher in G1 than in G2 showing a better vascular flow in the first population and EDV values are lower in G1 than in G2 showing less venous leakage.

However neurophysiological parameters did not show significant differences between both groups (BCR: G1: $38 \pm 8.7$ mseg vs G2: $34.6 \pm$ 10.11; NC: G1: $40.11 \pm 45.8$ m/seg vs G2: $12.4 \pm$ 23.1; PCEP: G1: $45.5 \pm 19.3$ $\mathrm{m} / \mathrm{seg}$ vs G2: $45.3 \pm 23.6-p>0.05)$.

CC-EMG showed asynchronous and asymmetrical potentials in G1 (minimal autonomic neuropathy) and denervation potentials in G2 characteristic of severe CC damage in this population (Figure 5).

We did not observe significant differences in LSCL questionnaire between both groups of diabetic patients.

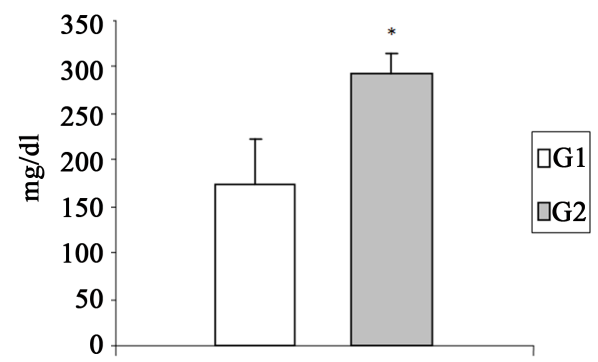

Figure 1. Average fasting glucose. At least 3 determinations were performed on each patient during the treatment period.

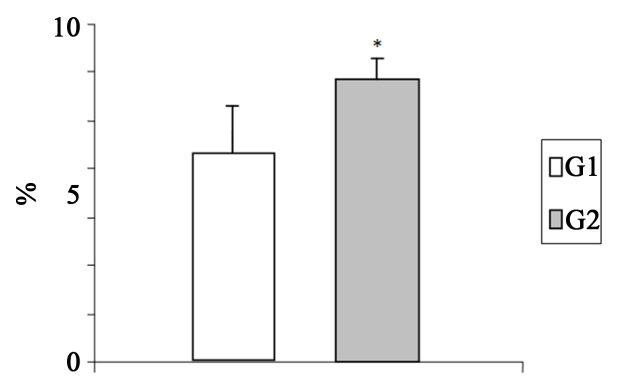

Figure 2. HbA1c determinations were performed at the end of the treatment with PDE5i. (Mean \pm SD; ${ }^{*} p<0.05$ ).

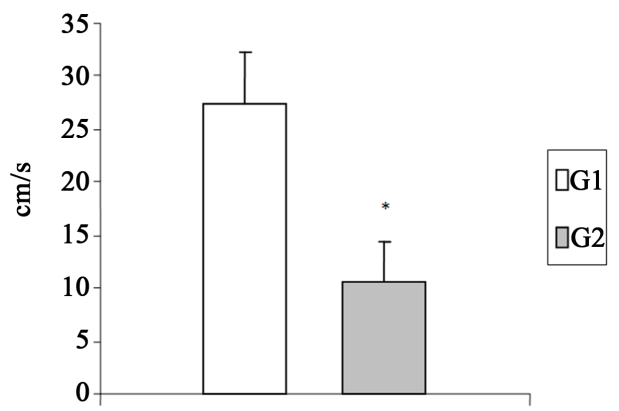

Figure 3. Penile doppler ultrasound after intracavernous administration of 20 mcg of prostaglandine E1. Evaluation of peack systolic velocity. (Mean $\left.\pm \mathrm{SD} ;{ }^{*} p<0.05\right)$. 


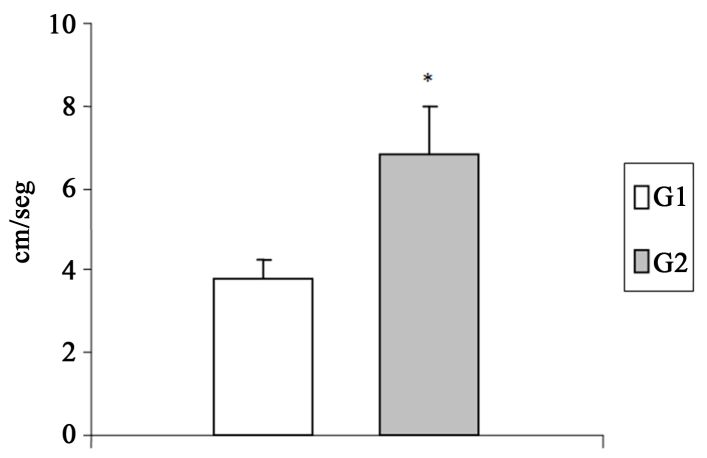

Figure 4. Penile doppler ultrasound after intracavernous administration of 20 mcg of prostaglandine E1. Evaluation of end diastolic velocity. (Mean \pm $\left.\mathrm{SD} ;{ }^{*} p<0.05\right)$.

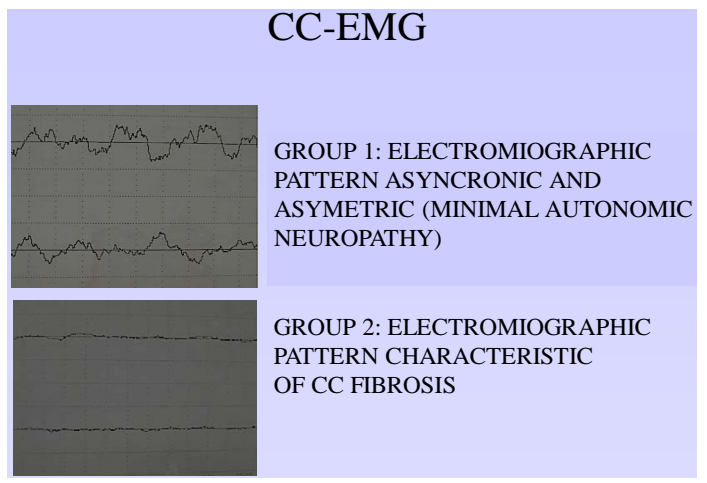

Figure 5. CC-electromiography by using contact electrodes.

\section{Discussion}

$\mathrm{DM}$ is the most prevalent chronic non infectious disease in the recent years. In diabetic men one of the most common complications is ED [2] [11]. It is estimated that between $20 \%$ to $50 \%$ of diabetic patients suffer from ED [12] [13].

The aim of our study was to evaluate functional alterations of the CC and its correlation with the lack of response to treatment with PDE5i in eugonadal patients with DM and ED. Oral therapy is the first choice for the treatment of ED. However these drugs show great variability in their effectiveness in diabetic population. Several studies have shown that PDE5i are effective in diabetic men with ED independently of HbA1c and glycemic concentration [14]. However our work did not show the same results. These parameters were significantly higher in G2 than in G1.

Dunsmuir and Holmes [15] using a lineal regression informatic model defined that the factors most significantly associated with ED in diabetic patients are: age, insulin treatment, retinopathy, symptomatic PN and symptomatic AN. Moreover Cellek et al. [16] observed that PN is associated with impaired neuronal blood flow and the formation of advanced glycation end products.

However, our results showed that only vascular alterations are associated with the lack of response to treatment with PDE5I. We did not observe PN in this population. In fact, several authors claim that microvascular disorders and endothelial dysfunction is the cause of ED in diabetic men [17]-[19].

CC-EMG showed that patients from G2 have more severe AN than G1 with denervation potentials characteristic of severe $\mathrm{CC}$ damage.

ED associated to DM can lead to a significant loss of life quality. It is therefore important to assess the effectiveness of available treatments. We did not observe significant differences in the LSCL questionnaire between both groups. This may be due to the fact that non responders to oral medication can access to other therapies as vasoactive drugs, vacuum devices or penile prosthetic implant.

In conclusion, our results showed that vascular and autonomic alterations are causes of severe CC damage and 
lack of response to treatment with PDE5i in this population. Peripheral neuropathy is not part of this process.

Penile vascular evaluation with Doppler ultrasound and CC-EMG are needed to predict the fiction of oral therapy with PDE5i in this population.

\section{Acknowledgements}

We thanks to Dr. Guillermo Lasalle for perform the CC-EMG for this study.

\section{References}

[1] Phé, V. and Rouprêt, M. (2012) Erectile Dysfunction and Diabetes: A Review of the Current Evidence-Based Medicine and a Synthesis of the Main Available Therapies. Diabetes \& Metabolism, 38, 1-13. http://dx.doi.org/10.1016/j.diabet.2011.09.003

[2] De Berardis, G., Francioisi, M., Belfiglio, M., Di Nardo, B., Greenfield, S., Kaplan, S.H., Pellegrini, F., Sacco, M., Tognoni, G., Valentini, M. and Nicolucci, A., Quality of Care and Outcomes in Type 2 Diabetes (QuED) Study Group (2002) Erectile Dysfunction and Quality of Life in Tipe 2 Diabetic Patients: A Serious Problem Too Often Overlooked. Diabetes Care, 25, 284-291. http://dx.doi.org/10.2337/diacare.25.2.284

[3] Lewis, R.W., Fugl-Meyer, K.S., Corona, G., Hayes, R.D., Laumann, E.O., Moreira Jr., E.D., Rellini, A.H. and Segraves, T. (2010) Definitions/Epidemiology/Risk Factors for Sexual Dysfunction. The Journal of Sexual Medicine, 7, 1598-1607. http://dx.doi.org/10.1111/j.1743-6109.2010.01778.x

[4] Kapur, V., Chien, C.V., Fuess, J.E. and Schwarz, E.R. (2008) The Relationship between Erectile Dysfunction and Cardiovascular Disease. Part II: The Role of PDE-5 Inhibition in Sexual Dysfunction and Cardiovascular Disease. Reviews in Cardiovascular Medicine, 9, 187-95.

[5] Nehra, A. (2009) Erectile Dysfunction and Cardiovascular Disease: Efficacy and Safety of Phosphodiesterase Type 5 Inhibitors in Men with Both Conditions. Mayo Clinic Proceedings, 84, 139-148. http://dx.doi.org/10.4065/84.2.139

[6] Awad, H., Salem, A., Gadalla, A., El Wafa, N.A. and Mohamed, O.A. (2010) Erectile Function in Men with Diabetes Type 2: Correlation with Glycemic Control. International Journal of Impotence Research, 22, 36-39. http://dx.doi.org/10.1038/ijir.2009.39

[7] Deyoung, L., Chung, E., Lovar, J.R., Romano, W. and Brock, G.B. (2012) Daily Use of Sildenafil Improves Endothelial Function in Men with Type 2 Diabetes. Journal of Andrology, 33, 176-80. http://dx.doi.org/10.2164/jandrol.111.013367

[8] Rosen, R.C. (1998) Quality of Life Assessment in Sexual Dysfunction Trials. International Journal of Impotence Research, 10, 21-23.

[9] Yang, M., Sontaq, A., Litman, H.J. and Rosen, R.C. (2013) Non Responders, Partial Responders and Complete Responders to PDE5 Inhibitors Therapy according to IIEF Criteria. Validation of an Author-Based Treatment Responder Classification. The Journal of Sexual Medicine, 10, 3029-3037. http://dx.doi.org/10.1111/jsm.12335

[10] Fugl-Meyer, A.R., Lodnert, G., Bränholm, I.B. and Fugl-Meyer, K.S. (1997) On Life Satisfaction in Male Erectile Dysfunction. International Journal of Impotence Research, 9, 141-148. http://dx.doi.org/10.1038/sj.ijir.3900269

[11] Hatzimouratidis, K. and Hatzichristou, D. (2014) How to Treat Erectile Dysfunction in Men with Diabetes: From Pathophysiology to Treatment. Current Diabetes Reports, 14, 545. http://dx.doi.org/10.1007/s11892-014-0545-6

[12] Martin-Morales, A., Sanchez-Cruz, J.J., Saenz de Tejada, I., Rodriguez-Vela, L., Jimenez-Cruz, J.F. and BurgosRodriguez, R. (2001) Prevalence and Independent Risk Factors for Erectile Dysfunction in Spain: Results of the Epidemiologystudy. The Journal of Urology, 166, 569-575. http://dx.doi.org/10.1016/S0022-5347(05)65986-1

[13] O’Donnell, A.B., Araujo, A.B. and McKinlay, J.B. (2004) The Health of Normally Agingmen: The Massachusetts Male Aging Study (1987-2004). Experimental Gerontology, 39, 975-984.

http://dx.doi.org/10.1016/j.exger.2004.03.023

[14] Fonseca, V., Seftel, A., Denne, J. and Fredlund, P. (2004) Impact of Diabetes Mellitus on the Severity of Erectile Dysfunction and Response to Treatment: Analysis of Data from Tadalafil Clinical Trials. Diabetologia, 4, 1914-1923. http://dx.doi.org/10.1007/s00125-004-1549-6

[15] Dunsmuir, W. and Holmes, S. (1996) Theaetiology and Management of Erectile, Eyaculatory and Fertility Problems in Men with Diabetes Mellitus. Diabetic Medicine, 13, 700-708. http://dx.doi.org/10.1002/(SICI)1096-9136(199608)13:8<700::AID-DIA174>3.0.CO;2-8

[16] Cellek, S., Cameron, N.E., Cotter, M.A. and Muneer, A. (2013) Pathophysiology of Diabetic Erectile Dysfunction: Potential Contribution of Vasa Nervorum and Advanced Glycation Endproducts. International Journal of Impotence Research, 25, 1-6. http://dx.doi.org/10.1038/ijir.2012.30 
[17] Ryan, J.G. and Gajra, J. (2012) Erectile Dysfunction and Its Association with Metabolic Syndrome and Endothelial Dysfunction among Patients with Type 2 Diabetes Mellitus. Journal of Diabetes and Its Complications, 26, 141-147. http://dx.doi.org/10.1016/j.jdiacomp.2011.12.001

[18] Naka, K.K., Papathanassiou, K., Bechlioulis, A., Kazakos, N., Pappas, K., Tigas, S., Makriyiannis, D., Tsatsoulis, A. and Michalis, L.K. (2012) Determinants of Vascular Functions in Patients with Type 2 Diabetes. Cardiovascular Diabetology, 11, 127. http://dx.doi.org/10.1186/1475-2840-11-127

[19] Shen, Y., Weng, S., Wang, J. and Tien, K. (2014) Erectile Dysfunction and Risk of End Stage Renal Disease Requiring Dialysis: A Nationwide Population-Based Study. PLoS ONE, 9, e102055.

http://dx.doi.org/10.1371/journal.pone.0102055 